\title{
Analisis Biaya Manfaat pada Proses Bisnis Sekolah
}

\author{
Muhammad Aji Pangestu ${ }^{1, *}$, Tanti Rismawati ${ }^{2}$, Muhammad Ainul Yaqin ${ }^{3}$ \\ Jurusan Teknik Informatika, Universitas Islam Negeri Maulana Malik Ibrahim, Indonesia \\ ${ }^{1} 17650065 @$ student.uin-malang.ac.id; 217650001@ student.uin-malang.ac.id; 3yaqinov@ti.uin-malang.ac.id \\ *corresponding author
}

INFO ARTIKEL

\section{Sejarah Artikel}

Diterima: 27 Desember 2020

Direvisi: 29 Januari 2021

Diterbitkan: 30 April 2021

Kata Kunci

Analisis Biaya Manfaat

Proses Bisnis

Proses Bisnis Sekolah

\begin{abstract}
ABSTRAK
Tujuan dari penelitian ini adalah menganalisis biaya yang diidentifikasi berdasarkan pada model proses bisnis organisasi sekolah. Kemudian mengidentifikasi manfaat yang diharapkan berdasarkan biaya yang telah direncanakan dan menentukan kelayakan dari investasi pembiayaan yang digunakan untuk proses bisnis sekolah. Metode yang digunakan dalam penelitian ini adalah Payback Period, Net Present Value, Benefit Cost Ratio, dan Return Of Investment yang digunakan untuk menentukan manfaat dari pembiayaan yang dikeluarkan. Pada penelitian ini peneliti menganalisis salah satu manfaat yang didapatkan dari pembiayaan yang dikeluarkan dalam proses bisnis sekolah berdasarkan Standar Nasional Pendidikan. Hasil yang didapat dalam biaya yang digunakan dalam analisis biaya manfaat proses bisnis sekolah adalah 175.000.000 sebagai investasi awal dan biaya operasional pada tahun ke-1 sebesar Rp6.200.000, pada tahun ke-2 sebesar Rp6.510.000, biaya pada tahun ke3 sebesar Rp6.835.500, pada tahun ke-4 sebesar Rp7.177.275, dan pada tahun ke-5 sebesar Rp7.536.139. Adapun manfaat pembiayaan proses bisnis disekolah ada 2 yaitu manfaat Tangiable dan Intangible. Manfaat Tangible sebesar 50.000.000 dan manfaat Intangible pembiayaan proses bisnis disekolah adalah peningkatan minat baca siswa sebesar 5\% pertahun, peningkatan kunjungan siswa ke perpustakaan sebesar $20 \%$ pertahun dan terjadi peningkatan prestasu akademis siswa sebesar $10 \%$ pertahun. Adapun Hasil yang didapat dalam analisis kelayakan diperoleh nilai Payback Period selama 5 tahun,nilai Net Present Value sebesar 10.769.071,63 dan Benefit Cost Ratio sebesar 1.00, Return Of Investment dalam pembiayaan proses bisnis sekolah adalah $19.46922381 \%$ dalam penelitian ini adalah 2.356151 yang berarti dalam jangka 5 tahun layak berinvestasi dalam proses bisnis sekolah berdasarkan Standar Nasional Pendidikan (SNP).
\end{abstract}

\section{PENDAHULUAN}

Sekolah adalah suatu institusi yang memiliki kekuatan atau kewenangan untuk menghasilkan generasi penerus bangsa dan negara[1]. Sebagai salah satu wadah penyelenggara pendidikan, Sekolah perlu memperhatikan beberapa komponen antara lain, sarana dan prasarana, kurikulum, pembiayaan, tenaga pendidik, dan peserta didik, serta komponen lain yang terkait dengan penyelenggaraan pendidikan. Pendidikan adalah upaya sadar dan terencana untuk menciptakan suasana belajar dan memungkinkan siswa untuk secara aktif mengembangkan potensinya, kekuatan spriritual keagamaan, pengendalian diri, kepribadian, berakhlak mulia, kecerdasan dan keterampilan yang diperlukan untuk dirinya, masyarakat dan negara[2].Pendidikan sekolah merupakan salah satu faktor penting untuk meningkatkan kualitas sumber daya manusia. Pada Undang-Undang Dasar 1945 pasal 31 berbunyi 31 "Tiap-tiap warga negara berhak mendapat pengajaran". Hal tersebut membuktikan keseimbangan pendidikan seluruh warga negara Indonesia [3]. 
Sekolah terdapat proses bisnis yang ada didalamnya, definisi dari proses bisnis adalah rangkaian aktivitas yang saling berkaitan untuk mencapai tujuan bisnis tertentu yang diselesaikan secara berurutan oleh manusia atau sistem didalam maupun diluar organisasi [4]. Proses bisnis di sekolah adalah aktivitas-aktivitas yang terjadi di sekolah. Setiap aktivitas yang dilakukan yang terdapat di sekolah dibutuhkan biaya akan hal tersebut.

Biaya merupakan pengorbanan sumber daya ekonomi, biasanya diukur mengunakan uang sebagai parameter yang telah terjadi atau mungkin terjadi untuk mencapai tujuan tertentu. Pembiayaan adalah salah satu kebutuhan pendidikan yang diharapkan menunjang semua kegiatan pendidikan baik secara formal maupun informal. Pendidikan dengan dukungan finansial yang memadai akan membawa pembelajaran yang maksimal. Pembiayaan didasarkan pada Standar Nasional Pendidikan terkait dengan Standar Nasional Pendidikan dalam Peraturan Pemerintah Nomor 19 Tahun 2005 yang merupakan standar minimal sistem pendidikan di seluruh wilayah hukum Negara Kesatuan Republik Indonesia. SNP terdiri dari 8 Standar yaitu Standar Isi, Standar Proses, Standar Sarana dan Prasarana, Standar Penilaian, Standar Kompetensi Lulusan, Standar Pendidik dan Tenaga Kependidikan, Standar Pengelolaan, dan Standar Pembiayaan[1]. Dalam literatur E-book yang berjudul "Pembiayaan Operasional Non Personalia untuk Optimalisasi Mutu Lulusan SMK" memiliki kelebihan yaitu didalamnya berisi pembiayaan berdasarkan Standar Nasional Pendidikan (SNP), akan tetapi hal tersebut memiliki kekurangannya yaitu belum membahas analisis biaya-manfaat sehingga belum dapat mengidentifikasi biaya dan manfaat pada proses bisnis yang telah dijalankan. Untuk mengatasi kekurangan tersebut dilakukan penelitian untuk mengidentifikasi biaya dan mengetahui manfaat yang diperoleh dari pembiayaan tersebut.

Penelitian ini bertujuan untuk menganalisis biaya yang diidentifikasi berdasarkan pada model proses bisnis organisasi sekolah dan mengetahui manfaat yang diharapkan berdasarkan biaya yang telah direncanakan. Analisis biaya manfaat digunakan sebagai alat dalam proses pengambilan keputusan untuk mengevaluasi kelayakan suatu proyek investasi proses bisnis sekolah berdasarkan Standar Nasional Pendidikan (SNP) dengan menggunakan metode Payback Period, Net Present Value (NPV), Benefit Cost Ratio (B/C Ratio), dan Return Of Investment. Metode tersebut digunakan dalam menganalisis kelayakan berinvestasi dalam proses bisnis sekolah[5].

\section{METODE}

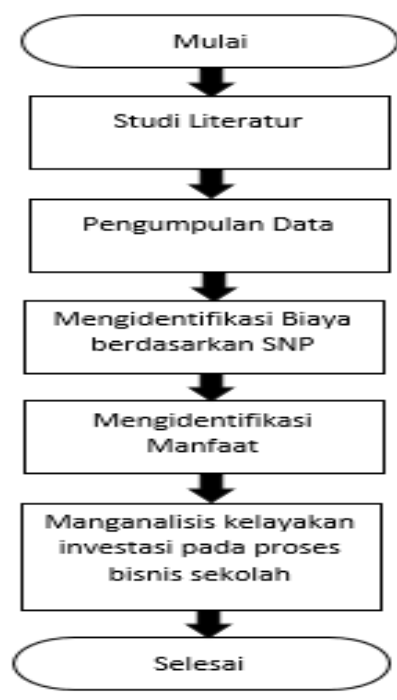

Gambar 1. Desain Eksperimen 
Desain eksperimen dalam penelitian ini adalah sebagaimana yang tertera pada Gambar

1. Pada Gambar 1, terdapat tahap-tahap desain eksperimen antara lain:

- Tahap Pertama dalam penelitian ini berawal dari pengumpulan studi literatur dengan mempelajari teori yang berasal dari buku, paper, jurnal, skripsi, tesis dan penelitian lain yang terkait dalam penelitian ini

- Tahap kedua adalah pengumpulan data yaitu terdapat data primer dan data sekunder. Data primer adalah kumpulan data yang dihasilkan secara langsung melalui objeknya. dan Data Sekunder merupakan kumpulan data yang diperoleh secara tidak langsung dan melalui media perantara contohnya dari penelitian sebelumnya yang terkait[6]. Dan data primer penelitian ini adalah pembiayaan proses bisnis sekolah. dan Data Sekunder penelitian ini adalah data yang berasal dari E-book yang berjudul "Pembiayaan Operasional Non Personalia untuk Optimalisasi Mutu Lulusan SMK" dan data yang kami gunakan adalah Pembiayaan Standar Proses untuk Penyelenggaraan Perpustakaan[7].

- Tahap ketiga adalah mengidentifikasi mengumpulkan dan meneliti data pembiayaan di sekolah yang telah terjadi pada proses bisnis sekolah. dalam hal ini terdapat biaya investasi untuk biaya penyelenggaraan perpustakaan sekolah pada tahun ke 0 , dan dan pada tahun selanjutnya pembiayaan operasional perpustakaan pada tahun berikutnya.

- Tahap Keempat adalah mengidentifikasi manfaat dari biaya yang timbul pada proses bisnis sekolah. manfaat pada proses sekolah dibagi menjadi 2 yaitu manfaat Tangible dan manfaat Intangible. Manfaat Tangible adalah manfaat yang berwujud yang dapat dijadikan penghematan ataupun peningkatan dari biaya proses bisnis sekolah yang dapat diukur dengan kuantitatif dalam bentuk satuan berupa uang. Sedangkan Manfaat Intangible adalah manfaat yang tidak bisa diukur secara ekonomis dan sulit diukur dalam bentuk satuan uang.[8]

- Tahap Kelima adalah Setelah mengidentifikasi biaya dan manfaat dari proses bisnis sekolah, maka selanjutnya adalah menganalisis kelayakan investasi menggunakan metode analisis biaya manfaat. dalam menganalisis tersebut dilakukan perhitungan dari biaya dan manfaat proses bisnis sekolah

\section{Metode Analisis Kelayakan Investasi}

Pada penelitian yang kami lakukan, kami menggunakan 4 metode kelayakan investasi untuk analisis proses bisnis sekolah, adapun metode tersebut adalah sebagai berikut:

1. Payback Period

Payback Period merupakan perhitungan untuk mencari berapa lama (dalam beberapa tahun) suatu investasi akan kembali. Penilaian proses bisnis dengan menggunakan metode ini didasarkan pada lamanya arus kas masuk dapat digunakan untuk membayar investasi, dan faktor bunga dimasukkan dalam perhitungan ini[9]. Dengan rumus sebagaimana Persamaan (1).

$$
\text { Payback Period }=n+\frac{a-b}{c-b} x 1 \text { tahun }
$$

Keterangan:

$\mathrm{n}=$ Tahun terakhir dimana arus kas belum menutupi biaya investasi

$\mathrm{a}=$ Biaya Investasi awal

$\mathrm{b}=$ jumlah kas yang masuk pada tahun ke-n

$\mathrm{c}=$ jumlah kas yang masuk pada tahun ke-n+1 
2. Net Present Value (NPV)

Net Present Value (NPV) merupakan selisih antara benefit (manfaat) dengan cost (biaya) yang telah diperkirakan manfaatnya/benefit dari kegiatan yang dilakukan. NPV menggunakan teknik arus kas yang didiskontokan[10]. Jika nilai Net Present Value (NPV)>1 maka dikategorikan Layak Berinvestasi. Jika nilai Net Present Value $($ NPV) $<1$ maka dikategorikan Tidak Layak Berinvestasi. NPV dapat dihitung dengan Persamaan (2):

$$
N P V=\sum_{t=1}^{n} \frac{C F_{t}}{(1+r)^{t}}-I
$$

Keterangan:

$\mathrm{CF}_{\mathrm{t}}=$ jumlah kas yang masuk pada periode $\mathrm{t}$

I= Biaya yang dibutukan dalam Investasi

$\mathrm{r}=$ nilai discount rate

$\mathrm{t}=$ Jumlah periode arus kas yang masuk

$\mathrm{n}=$ umur proses bisnis sekolah (dalam tahun)

\section{Benefit Cost Ratio}

Benefit Cost Ratio merupakan perbandingan antara jumlah nilai sekarang yang berasal dari pendapatan (benefit) dengan pengeluaran (cost) dari Proses Bisnis Standar pembiayaan yang ada di sekolah[10]. Metode ini digunakan untuk mengevaluasi proses bisnis yang ada di dalam sekolah dan penekanannya ditunjukkan kepada manfaat bagi kepentingan umum sekolah.Adapun rumus untuk menghitung Benefit Cost Ratio adalah sebagaimana Persamaan (3)

$$
N E T \frac{B}{R}=\frac{\sum_{t=1}^{n} \frac{B_{t}-C_{t}}{(1+i)^{t}}}{\sum_{t=1}^{n} \frac{B_{t}-C_{t}}{(1+i)^{t}}}
$$

Keterangan:

Net $\mathrm{B} / \mathrm{C}=$ Nilai Net Benefit Cost Ratio

$\mathrm{B}_{\mathrm{t}}=$ manfaat yang dihasilkan di tahun ke- $\mathrm{t}$

$\mathrm{C}_{\mathrm{t}}=$ Biaya di tahun ke- $\mathrm{t}$

$\mathrm{I}=$ Discount Factor

$\mathrm{t}=$ Umur proses bisnis sekolah

Indikator NET B/C adalah jika nilai Net B/C lebih dari 1 , maka proses bisnis sekolah layak untuk dilaksanakan. Jika nilai Net B/C kurang dari 1, maka proses bisnis sekolah tidak layak untuk dilaksanakan

\section{Return of Investment}

Return of Investment (ROI) merupakan Suatu bentuk profitabilitas yang dirancang untuk mengukur kemampuan sekolah dengan total dana yang diinvestasikan pada aset yang menghasilkan keuntungan dalam proses bisnis sekolah. Return on Investment (ROI) mengukur seberapa besar pendapatan bersih yang diperoleh dari semua aset yang dimiliki oleh sekolah[11]. Dengan rumus perhitungan sebagaimana Persamaan (4): 


$$
R O I=\frac{(\text { Manfaat }- \text { Biaya })}{\text { Biaya }} \times 100 \%
$$

\section{HASIL DAN PEMBAHASAN}

Pada desain penelitian yang kami gunakan, terdapat 3 tahap dalam proses penentuan analisis biaya-manfaat dari proses bisnis sekolah, adapun 3 tahap tersebut kami jelaskan sebagai berikut:

\section{Identifikasi Biaya Proses Bisnis Sekolah Berdasarkan Standar Nasional Pendidikan}

Standar pembiayaan sekolah yang kami gunakan adalah Standar Proses untuk penyelenggaraan perpustakaan. Kami asumsikan nilai biaya investasi awal pembangunan perpustakaan sebesar Rp.175.000.000, dan biaya komponen penyelenggaraan perpustakaan tertera pada tabel dibawah ini.

Tabel 1. Biaya Komponen penyelenggaraan perpustakaan

\begin{tabular}{|c|c|c|c|c|}
\hline No & Deskripsi & Frekuensi & Total Biaya & $\begin{array}{l}\text { Total Biaya Per } \\
\text { Tahun }\end{array}$ \\
\hline 1 & Buku Tulis & semester & Rp150.000 & Rp300.000 \\
\hline 2 & Plastik Sampul & tahun & Rp560.000 & Rp560.000 \\
\hline 3 & Gunting & semester & Rp52.500 & Rp105.000 \\
\hline 4 & Cutter & semester & Rp62.500 & Rp125.000 \\
\hline 5 & Kapur Barus & semester & Rp30.000 & Rp60.000 \\
\hline 6 & $\begin{array}{l}\text { Pengadaan Kartu Anggota } \\
\text { Perpustakaan }\end{array}$ & tahun & Rp1.080.000 & Rp1.080.000 \\
\hline 7 & Stiker & tahun & Rp500.000 & Rp500.000 \\
\hline 8 & Kartu Buku & tahun & Rp250.000 & Rp250.000 \\
\hline 9 & Bantalan Stempel & tahun & Rp35.000 & Rp35.000 \\
\hline 10 & Tinta Stempel & tahun & Rp20.000 & Rp20.000 \\
\hline 11 & Steples Kecil & semester & Rp65.500 & Rp131.000 \\
\hline 12 & Isi Steples & tahun & Rp23.000 & Rp23.000 \\
\hline 13 & Lem & semester & Rp33.500 & Rp67.000 \\
\hline 14 & Pulpen & semester & Rp45.000 & Rp90.000 \\
\hline 15 & Penghapus Tinta & semester & Rp24.500 & Rp49.000 \\
\hline 16 & Penggaris & semester & Rp24.000 & Rp48.000 \\
\hline 17 & Langganan Koran & semester & Rp350.000 & Rp700.000 \\
\hline 18 & Langganan Majalah & semester & Rp250.000 & Rp500.000 \\
\hline 19 & Langganan Internet & semester & Rp750.000 & Rp1.500.000 \\
\hline \multicolumn{4}{|c|}{ Jumlah } & Rp6.143.000 \\
\hline
\end{tabular}


Pada Tabel 1. dijelaskan tentang komponen penyelenggaraan perpustakaan. Untuk frekuensi apabila dalam bentuk semester akan dikalikan 2, sedangkan jika dalam bentuk tahun maka biayanya tetap karena total biaya dihitung dalam tahunan. dan biaya yang digunakan untuk penyelenggaraan perpustakaan dan pada tahun ke-0 atau tahun awal investasi sampai tahun ke-5 akan tertera pada Tabel 2.

Tabel 2. Pembiayaan Operasional Per Tahun

\begin{tabular}{|l|l|l|}
\hline Tahun Ke- & Kenaikan biaya & Pembiayaan \\
\hline 0 & $0 \%$ & $\mathrm{Rp} 175.000 .000$ \\
\hline 1 & $0 \%$ & $\mathrm{Rp} 6.200 .000$ \\
\hline 2 & $5 \%$ & $\mathrm{Rp} 6.510 .000$ \\
\hline 3 & $5 \%$ & $\mathrm{Rp} 6.835 .500$ \\
\hline 4 & $5 \%$ & $\mathrm{Rp} 7.177 .275$ \\
\hline 5 & $5 \%$ & $\mathrm{Rp} 7.536 .139$ \\
\hline
\end{tabular}

Berdasarkan Tabel 2. diketahui kenaikan biaya per tahun adalah sebesar 5\% dan diketahui biaya operasional pada tahun ke-1 sebesar Rp6.200.000, pada tahun ke-2 sebesar Rp6.510.000, pada tahun ke-3 sebesar Rp6.835.500, biaya pada tahun ke-4 sebesar Rp7.177.275, dan pada tahun ke-5 sebesar Rp7.536.139. Dari data tabel 1 dan 2 akan kami analisis manfaat biaya yang dikeluarkan pada tahap selanjutnya.

\section{Identifikasi Manfaat Proses Bisnis Sekolah}

1. Manfaat Tangible

Manfaat tangible adalah manfaat langsung yang bisa dijadikan acuan uang. Adapun manfaat tangible penyelenggaraan perpustakaan adalah sebagaimana Tabel 3.

Tabel 3. Manfaat Tangible

\begin{tabular}{|l|l|l|l|l|l|}
\hline No & Manfaat Tangible & Deskripsi & $\begin{array}{l}\text { Jumlah } \\
\text { manfaat }\end{array}$ & $\begin{array}{l}\text { Manfaat yang } \\
\text { dihasilkan }\end{array}$ & $\begin{array}{l}\text { Total manfaat } \\
\text { keseluruhan }\end{array}$ \\
\hline 1 & $\begin{array}{l}\text { Peningkatan mutu } \\
\text { sarana belajar } \\
\text { sekolah }\end{array}$ & $\begin{array}{l}\text { Peningkatan Mutu sekolah dapat } \\
\text { terealisasi apabila sarana belajar dapa } \\
\text { terpenuhi, oleh karena itu dibutuhkan } \\
\text { perpustakaan untuk mendukung sarana } \\
\text { belajar mengajar, asumsikan bahwa } \\
\text { sekolah dapat menghemat sebesar 5 } \\
\text { juta rupiah pertahun untuk setiap } \\
\text { pengadaan sarana pendukung belajar } \\
\text { diluar kelas }\end{array}$ & 1 Sekolah & Rp5.000.000 & Rp5.000.000 \\
& & & & \\
\hline
\end{tabular}




\begin{tabular}{|c|c|c|c|c|c|}
\hline 2 & $\begin{array}{l}\text { Pengurangan biaya } \\
\text { bahan ajar } \\
\text { pendukung bagi guru } \\
\text { dan staff }\end{array}$ & $\begin{array}{l}\text { Pengurangan biaya pencarian literatur } \\
\text { pendidikan bagi guru dikarenakan } \\
\text { setiap bahan ajar pendukung dapat } \\
\text { digunakan bergantian oleh para guru } \\
\text { dalam setiap } 200 \text { guru dapat } \\
\text { menghemat pembiayaan pembelian } \\
\text { bahan ajar bagi guru sebesar } \\
\text { Rp. } 200.000 \text { per guru }\end{array}$ & $\begin{array}{l}50 \text { guru } \\
\text { dan } \\
\text { karyawan }\end{array}$ & Rp200.000 & Rp10.000.000 \\
\hline 3 & $\begin{array}{l}\text { Pengurangan biaya } \\
\text { pembelian buku bagi } \\
\text { siswa }\end{array}$ & $\begin{array}{l}\text { biaya pembelian buku paket maupun } \\
\text { buku pendukung siswa dapat dikurangi } \\
\text { dikarenakan perpustakaan dapat } \\
\text { meminjamkan ke semua siswa. }\end{array}$ & $\begin{array}{l}200 \\
\text { siswa }\end{array}$ & Rp100.000 & Rp20.000.000 \\
\hline 4 & $\begin{array}{l}\text { Pengurangan biaya } \\
\text { pembelian langganan } \\
\text { bahan baca edukasi }\end{array}$ & $\begin{array}{l}\text { dengan adanya perpustakaan setiap } \\
\text { warga sekolah dapat melihat koran } \\
\text { berita maupun majalah terbaru untuk } \\
\text { menggiatkan minat baca dikarenakan } \\
\text { sekolah mengadakan langganan untuk } \\
\text { satu sekolah. }\end{array}$ & 1 sekolah & Rp.10.000.000 & Rp10.000.000 \\
\hline 5 & $\begin{array}{l}\text { pengurangan biaya } \\
\text { operasional } \\
\text { pengadaan buku bagi } \\
\text { siswa }\end{array}$ & $\begin{array}{l}\text { pengurangan biaya operasional } \\
\text { pengadaan buku bagi siswa } \\
\text { dikarenakan setiap tahun biaya } \\
\text { operasional tersebut hanya digunakan } \\
\text { untuk memperbaiki buku atau } \\
\text { mengganti buku yang telah rusak }\end{array}$ & 200 & Rp25.000 & Rp5.000.000 \\
\hline \multicolumn{5}{|c|}{ Total } & Rp50.000.000 \\
\hline
\end{tabular}

Berdasarkan Tabel 3. diketahui manfaat tangible proses bisnis sekolah adalah peningkatan mutu sarana belajar sekolah sebesar 5.000.000, pengurangan biaya bahan ajar pendukung bagi guru dan staff sebesar 10.000.000, pengurangan biaya pembelian langganan bahan baca edukasi sebesar 10.000.000, pengurangan biaya operasional pengadaan buku bagi siswa sebesar 5.000.000. Dan total keseluruhan manfaat tangible proses bisnis sekolah adalah 50.000 .000

\section{Manfaat Intangible}

Berdasarkan pembiayaan proses bisnis sekolah penyelenggaraan perpustakaan didapatkan manfaat intangible yang terdiri atas

Tabel 4. Manfaat Intangible

\begin{tabular}{|l|l|l|}
\hline No & Manfaat Intangible & Deskripsi \\
\hline 1 & Peningkatan minat baca siswa & $\begin{array}{l}\text { Dengan adanya perpustakaan minat belajar } \\
\text { siswa mengalami peningkatan sebesar 5\% } \\
\text { pertahun }\end{array}$ \\
\hline 2 & Peningkatan kunjungan ke perpustakaan & $\begin{array}{l}\text { Peningkatan kunjungan siswa ke } \\
\text { perpustakaan sebesar 20\% pertahun }\end{array}$ \\
\hline 3 & Peningkatan prestasi akademis siswa & $\begin{array}{l}\text { Dengan adanya perpustakaan prestasi } \\
\text { akademis siswa meningkat sebesar 10\% } \\
\text { per tahun }\end{array}$ \\
\hline
\end{tabular}


Berdasarkan Tabel 4. diatas diketahui manfaat intangible pembiayaan proses bisnis disekolah adalah peningkatan minat baca siswa sebesar 5\% pertahun, peningkatan kunjungan siswa ke perpustakaan sebesar $20 \%$ pertahun dan terjadi peningkatan prestasu akademis siswa sebesar $10 \%$ pertahun.

\section{Analisis Kelayakan Investasi}

1. Analisis Kelayakan menggunakan Payback Period

Adapun besaran manfaat proses bisnis sekolah setiap tahunnya sebesar Rp. 50.000.000 per tahun dan jangka investasi selama 5 tahun adapun nilai Payback Period per tahun adalah sebagaimana Tabel 5.

Tabel 5. Perhitungan Nilai Payback Period

\begin{tabular}{|l|l|l|l|}
\hline Tahun & Manfaat & Biaya & Nilai Payback Period \\
\hline 0 & Rp0 & Rp175.000.000 & -Rp175.000.000 \\
\hline 1 & Rp50.000.000 & Rp6.200.000 & -Rp131.200.000 \\
\hline 2 & Rp50.000.000 & Rp6.510.000 & - Rp87.710.000 \\
\hline 3 & Rp50.000.000 & Rp6.835.500 & -Rp44.545.500 \\
\hline 4 & Rp50.000.000 & Rp7.177.275 & -Rp1.722.775 \\
\hline 5 & Rp50.000.000 & Rp7.536.139 & Rp40.741.086 \\
\hline
\end{tabular}

Pada Tabel 5. dapat diketahui nilai Payback Period pada tahun ke-0 sebesar Rp175.000.000, pada tahun ke-1 sebesar -Rp131.200.000, pada tahun ke-2 sebesar Rp87.710.000, pada tahun ke-3 sebesar -Rp44.545.500, pada tahun ke-4 sebesar Rp1.722.775, dan pada tahun ke-5 sebesar Rp40.741.086. Hal tersebut berarti pada tahun ke-5 nilai Payback Period menjadi positif. Dapat disimpulkan bahwa dalam waktu 5 tahun sekolah sudah mendapat pengembalian dana investasi.

2. Analisis Kelayakan menggunakan Net Present Value

Pada perhitungan menggunakan Metode Net Present Value terdapat Net Cash Flow. Net Cash Flow kami dapatkan dari hasil manfaat dikurangi pembiayaan dan diasumsikan discount rate sebesar 5\% Adapun hasilnya adalah sebagaimana Tabel 6.

Tabel 6. Perhitungan nilai Net Present Value

\begin{tabular}{|l|l|l|l|l|}
\hline Tahun & Net Cash Flow & Discount Rate & Discount Factor & $P$ V \\
\hline$(\mathrm{a})$ & (b) & (c) & $(\mathrm{d})=1 /\left(1+(\mathrm{c})^{\wedge} \mathrm{a}\right)$ & $(\mathrm{e})=(\mathrm{b})^{*}(\mathrm{~d})$ \\
\hline 1 & $\mathrm{Rp} 43.800 .000$ & $5 \%$ & 0,9523809524 & $\mathrm{Rp} 41.419 .048$ \\
\hline 2 & $\mathrm{Rp} 43.490 .000$ & $5 \%$ & 0,9070294785 & $\mathrm{Rp} 39.151 .474$ \\
\hline 3 & $\mathrm{Rp} 43.164 .500$ & $5 \%$ & 0,8638375985 & $\mathrm{Rp} 36.991 .880$ \\
\hline 4 & $\mathrm{Rp} 42.822 .725$ & $5 \%$ & 0,8227024748 & $\mathrm{Rp} 34.935 .124$ \\
\hline 5 & $\mathrm{Rp} 42.463 .861$ & $5 \%$ & 0,7835261665 & $\mathrm{Rp} 33.271 .546$ \\
\hline \multicolumn{2}{|l|}{ Total Present Value Selama Lima Tahun } & & $185.769 .071,63$ \\
\hline
\end{tabular}


NPV (Total PV- Investasi)

$10.769 .071,63$

Pada Tabel 6. diketahui nilai Present Value (PV) dalam 5 tahun adalah 185.769.071,6 . Dan diperoleh hasil Net Present Value (NPV) adalah sebesar 10.769.071,63, hal tersebut menunjukkan bahwa nilai NPV dapat dikategorikan LAYAK BERINVESTASI.

3. Analisis Kelayakan Menggunakan Benefit Cost Ratio

Pada perhitungan menggunakan Benefit Cost Ratio. kelayakan investasi proses bisnis penyelenggaraan perpustakaan diperoleh hasil pada Tabel 7.

Tabel 7. Perhitungan Nilai Benefit Cost Ratio

\begin{tabular}{|l|l|l|l|l|l|}
\hline Tahun & Manfaat & Biaya & $\begin{array}{l}\text { Fet Cash } \\
\text { Flow }\end{array}$ & $\begin{array}{l}\text { Discount } \\
\text { Factor (5\%) }\end{array}$ & $\boldsymbol{P V}$ \\
\hline 1 & Rp50.000.000 & Rp6.200.000 & Rp43.800.000 & 0,9523809524 & Rp41.714.286 \\
\hline 2 & Rp50.000.000 & Rp6.510.000 & Rp43.490.000 & 0,9070294785 & Rp39.446.712 \\
\hline 3 & Rp50.000.000 & Rp6.835.500 & Rp43.164.500 & 0,8638375985 & Rp37.287.118 \\
\hline 4 & Rp50.000.000 & Rp7.177.275 & Rp42.822.725 & 0,8227024748 & Rp35.230.362 \\
\hline 5 & Rp50.000.000 & Rp7.536.139 & Rp42.463.861 & 0,7835261665 & Rp33.271.546 \\
\hline Benefit Selama 3 Tahun & & & Rp186.950.024 \\
\hline Total Biaya Awal Investasi & & & Rp175.000.000 \\
\hline B/C
\end{tabular}

Pada Tabel 7. diketahui nilai Benefit Cost Ratio sebesar 1,00 hal tersebut berarti nilai investasi berdasarkan nilai Benefit Cost Ratio dapat dikategorikan LAYAK BERINVESTASI.

4. Analisis Kelayakan Menggunakan Return Of Investment (ROI)

Pada perhitungan menggunakan Return Of Investment (ROI). kelayakan investasi proses bisnis penyelenggaraan perpustakaan diperoleh hasil pada Tabel 8.

Tabel 8. Perhitungan Nilai Return Of Investment (ROI)

\begin{tabular}{|l|l|l|}
\hline Tahun Ke- & Manfaat & Pembiayaan \\
\hline 0 & $\mathrm{Rp} 0$ & $\mathrm{Rp} 175.000 .000$ \\
\hline 1 & $\mathrm{Rp50.000.000}$ & $\mathrm{Rp} 6.200 .000$ \\
\hline 2 & $\mathrm{Rp50.000.000}$ & $\mathrm{Rp} 6.510 .000$ \\
\hline 3 & $\mathrm{Rp50.000.000}$ & $\mathrm{Rp} 6.835 .500$ \\
\hline 4 & $\mathrm{Rp50.000.000}$ & $\mathrm{Rp} 7.177 .275$ \\
\hline 5 & $\mathrm{Rp50.000.000}$ & $\mathrm{Rp} 7.536 .139$ \\
\hline Total & $\mathrm{Rp} 250.000 .000$ & $\mathrm{Rp} 209.258 .914$ \\
\hline Nilai ROI & & $19,46922381 \%$ \\
\hline
\end{tabular}


Pada Tabel 8. diketahui nilai Return Of Investment (ROI) sebesar 19,46922381\% hal tersebut berarti nilai investasi berdasarkan nilai Return Of Investment (ROI) dapat dikategorikan LAYAK BERINVESTASI. Adapun hasil yang didapat dari penelitian yang dilakukan terdapat pada Tabel 9.

Tabel 9. Hasil Penelitian

\begin{tabular}{|l|l|l|}
\hline Metode & Hasil & Keterangan \\
\hline Payback period & 5 Tahun & $\begin{array}{l}\text { Dalam waktu 5 tahun sekolah } \\
\text { akan mendapat pengembalian } \\
\text { biaya investasi }\end{array}$ \\
\hline Net Present Value & $10.769 .071,63$ & $\begin{array}{l}\text { Nilai Net Present Value > 1, } \\
\text { maka layak berinvestasi }\end{array}$ \\
\hline Benefit Cost Ratio & 1,00 & $\begin{array}{l}\text { Nilai Benefit Cost Ratio >1, } \\
\text { maka layak berinvestasi }\end{array}$ \\
\hline Return Of Investment & $19.46922381 \%$ & $\begin{array}{l}\text { Nilai manfaat dari proyek yang } \\
\text { dijalankan sebesar } \\
19.46922381 \%\end{array}$ \\
\hline
\end{tabular}

Berdasarkan Tabel 9, diketahui hasil analisis kelayakan proses bisnis sekolah berdasarkan Standar Nasional Pendidikan (SNP) menggunakan metode payback peroid, net present value, benefit cost ratio, dan return of investment layak untuk berinvestasi.

\section{KESIMPULAN}

Kesimpulan pada penelitian ini adalah biaya yang digunakan dalam analisis biaya manfaat proses bisnis sekolah adalah 175.000.000 sebagai investasi awal dan biaya operasional pada tahun ke-1 sebesar Rp6.200.000, pada tahun ke-2 sebesar Rp6.510.000, biaya pada tahun ke-3 sebesar Rp6.835.500, pada tahun ke-4 sebesar Rp7.177.275, dan pada tahun ke-5 sebesar Rp7.536.139. Adapun manfaat pembiayaan proses bisnis disekolah ada 2 yaitu manfaat Tangiable dan Intangible. Manfaat Tangible sebesar 50.000.000 dan manfaat Intangible pembiayaan proses bisnis disekolah adalah peningkatan minat baca siswa sebesar 5\% pertahun, peningkatan kunjungan siswa ke perpustakaan sebesar 20\% pertahun dan terjadi peningkatan prestasu akademis siswa sebesar 10\% pertahun. Adapun Hasil yang didapat dalam analisis kelayakan diperoleh nilai Payback Period selama 5 tahun,nilai Net Present Value sebesar 10.769.071,63 dan Benefit Cost Ratio sebesar 1.00, ROI dalam pembiayaan proses bisnis sekolah adalah $19.46922381 \%$ dalam penelitian ini adalah 2.356151 yang berarti dalam jangka 5 tahun layak berinvestasi dalam proses bisnis sekolah.

\section{REFERENSI}

[1] R. T. E. Margareta and B. Ismanto, "Strategi Perencanaan Pembiayaan Sekolah dalam Peningkatan Mutu di SMP Negeri,” Kelola J. Manaj. Pendidik., vol. 4, no. 2, p. 195, 2017.

[2] Yoto, "Analisis Pembiayaan di Indonesia (Suatu Kajian Praktis dalam Sistem Pengelolaan Anggaran Pendidikan pada Sekolah Menengah Umum dan Kejuruan)," J. Tek. Mesin, vol. 20, no. 1, pp. 78-93, 2012.

[3] F. W. P, "Pembiayaan Pendidikan: Suatu Kajian Teoritis," J. Pendidik. dan Kebud., vol. 19, no. 4, p. $565,2013$.

[4] S. K. Sari and A. Asniar, "Analisis Dan Pemodelan Proses Bisnis Prosedur Pelaksanaan Proyek Akhir Sebagai Alat Bantu Identifikasi Kebutuhan Sistem,” J. Inform. dan Elektron., vol. 7, no. 2, 2015. 
[5] Alfiarini, “Analisis Manfaat dan Biaya dalam penyelenggaraan Pendidikan E-learning di Perguruan Tinggi," J. Komtekinfo, vol. 2, no. 2, pp. 57-61, 2015.

[6] J. Ilmiah, A. Cinta, and D. Istari, "PEMBANGUNAN MELALUI PROGRAM NASIONAL PENGEMBANGAN EKONOMI LOKAL ( Proyek KasusDs . Sidomulyo, Kec . Purwoasri , Kediri ) Jurnal Ilmiah Disusun oleh : Adhistya Cinta Dhama Istari,” 2014.

[7] I. Sujadi, A. Rahmawati, A. Budianto, D. Octoria, and Kristiandi, Pembiayaan Operasional Non Personalia untuk Optimalisasi Mutu Lulusan SMK. Direktorat Pembinaan Sekolah Menengah Kejuruan Kementrian Pendidikan dan Kebudayaan, 2018.

[8] RAKA ARYO KINANTHI, "Informasi Pendistribusian Produk Menggunakan Metode Cost Benefit Analysis Pada Pt . Guna Atmaja Jaya Analysis of Investment Feasibility Information System for Distributing Products Using Cost Benefit Analysis Method in Pt . Guna Atmaja Jaya,” 2017.

[9] I. Sulianti and L. F. Tilik, "Analisis Kelayakan Finansial Internal Rate of Return (IRR) dan Benefit Cost Ratio (BCR) pada Alternatif Besaran Teknis Bangunan Pasar Cinde Palembang," Pilar, vol. 8, no. $1,2013$.

[10] G. Prabantoro, "Mengukur Kelayakan Ekonomis Proyek Sistem Informasi Manajemen Menggunakan Metode 'Cost \& Benefits Analysis' Dan Aplikasinya Dengan MS EXCEL 2000," Sist. Inf. Manaj. Sains Manaj. STIE Indones., pp. 1-14, 2000.

[11] R. Wau, Achmad Syarifuddin, and R. Herwanto, "Analisis Perbandingan Economic Value Added (EVA) dan Return On Investment (ROI) Dalam Menilai Kinerja Keuangn Sub Sektor Farmasi yang Terdapat di Bursa Efek Indonesia,” Bus. Stud., vol. 02, no. 01, pp. 99-110, 2017.

[12] A. Astuty and N. R. H Anwar, "Analisis Biaya Manfaat Pembangunan Pltmg Pada Sistem Kelistrikan Kepulauan Selayar," Patria Artha Technol. J., vol. 2, no. 2, pp. 76-82, 2018. 